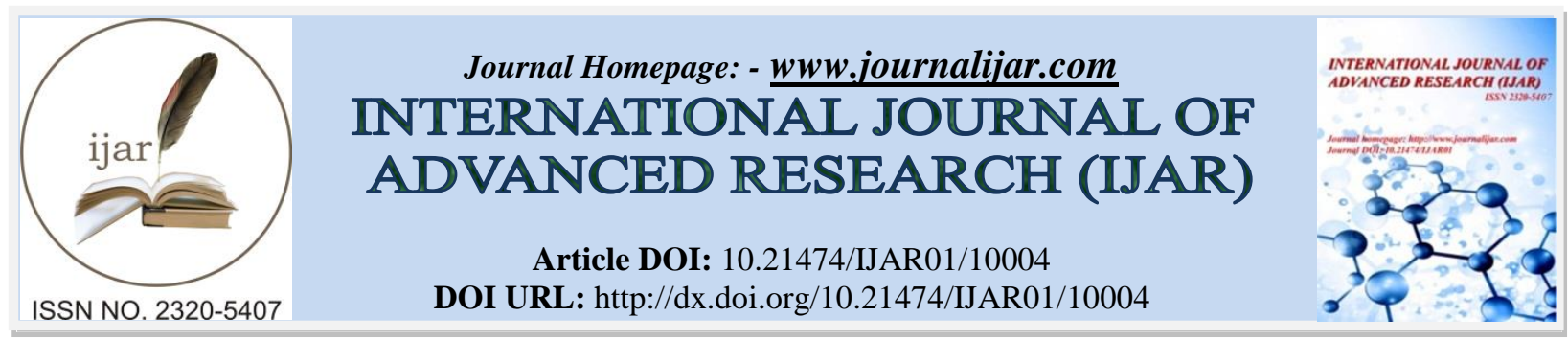

RESEARCH ARTICLE

\title{
ENGAGING IN COMMUNITIES OF PRACTICE IN HIGHER EDUCATION: A PERSONAL JOURNEY.
}

Todd Jobbitt.

Graduate School of Education, Hankuk University of Foreign Studies, 270 Imun-dong, Dongdaemun-gu, Seoul, 130-791, Korea.

\section{Manuscript Info}

\section{Manuscript History}

Received: 05 September 2019

Final Accepted: 07 October 2019

Published: November 2019

Key words:-

communities of practice, reflective practice, teacher professional identity.

\section{Abstract}

Clarifying one's own development as a teacher within educational institutions can be a complicated journey of self-discovery, but the good news is that this does not need to be a solitary pursuit. Within higher educational institutions, communities of practice have consistently formed to allow for the transition of novice instructors toward more enlightened ones. How this process occurs, how it is defined, and the implications of such practice are the focus of this paper. By examining these aspects, one can perhaps find a more solid footing upon which to continue upon the path of professional development within such institutions. The author will show his own journey of discovery via early graduate school events, culminating in a pathway toward yearly academic publishing requirements. The author ends with some helpful suggestions for improving one's development in this area.

Copy Right, IJAR, 2019,. All rights reserved.

\section{Introduction:-}

Engin and Atkinson (2015) correctly observed that although "Professional development (PD) of teaching staff in K12 education is a widely accepted part of the professional activity of teaching...it is not always seen as a crucial strand of academic faculty development in higher education" (p. 164). This observation can be no more evident than to one teaching in-between K-12 and higher education, in private academy teaching. An even more challenging aspect of this position, for me, was determining how to pursue professional development.

In my early teaching career in mid-1990's Korea, I had reached a crossroads in my journey of pursuing professional development. As a novice teacher with only an undergraduate degree, I did my best to meet students' and stakeholders' expectations in the fulfillment of my teaching duties. Over time, my growth in this environment expanded between how I was teaching and how I wanted to teach, which influenced me continue further in the language teaching field. What became clear after working for a few years was that more professional development was needed for me to reach what I perceived as my full potential.

The valuable learning that occurred from my experience in Korea helped me gain a greater awareness, at that time, of what future teaching contexts could do for my career in teaching. There are a great variety of schools with differences of opinion about 'community' and what it means to be 'professional' but it can be a matter of not knowing what either is, too. For example, in my early teaching I had presumed that 'being professional' meant presenting as much material in as efficient a manner as possible, primarily due to the private school context in which

Corresponding Author:- Todd Jobbitt.

Address:- Graduate School of Education, Hankuk University of Foreign Studies, 270 Imun-dong, Dongdaemun-gu, Seoul, 130-791, Korea. 
I taught. Given the Korean business model of teaching of the late 1990's, this was not an unusual practice or observation.

Although I had taught only at Korean academies, I learned a great deal about the business of education. I recognized that academies filled a specific niche in English education that was vital for L2 students who otherwise would have not had their learning needs met. Learning about teaching in this format nurtured my sense of teacher identity and was a springboard to future teaching goals; the set curriculum substituted for my lack of knowledge about what to teach.

The academy format allowed me the time needed to question the type of teaching that I wanted to pursue professionally. Although initially helpful, it mostly involved activities and techniques. My personal needs as a developing teacher had moved beyond this, however, with the differences manifesting in my approach to the quality of the learning and teaching experience. I felt that I was, in the words of Woods (1994), "...having too much work to do, together with a strong moral imperative to do it but not enough time or energy". Attending The School for International Training (now SIT Graduate Institute) in the Fall of 2002 was a new turning point for me, especially in terms of developing a community of teachers.

The difference in defining 'community' and 'being professional' for me, have changed significantly since attending graduate school in the early 2000's. If having a better sense of self which increases my teaching confidence regardless of content and context means professionalism, then I definitely developed at that time. The type of 'democratic learning community' (Welton, 1995) and its emphasis on dialogue that I learned school truly helped me make great strides on my teacher-learner pathway. Hargreaves and Lo $(2000$, p. 1) note that it is teachers who are the lode-bearers for the sharing of knowledge and building of communities, despite challenging teaching contexts and societal demands. Despite my own challenges, examining the complexities between learning and teaching became easier over time, and I gained a confidence about being able to facilitate and motivate students.

\section{Literature Review}

There are many names for 'professional development' in academic literature. Engin \& Atkinson (2015), cite several helpful examples and sources: "peer observations (Bell \& Mladenovic, 2008; Cosh, 1999; Lomas \& Kinchin, 2006), observations from supervisors (Gosling, 2002), and formal faculty appraisal (Murdoch, 2000), (p. 164). One other name coined in this area is the more socially-constructed activity of a 'faculty learning community' (FLC) (Lave, 1991, as cited in Engin \& Atkinson, 2015, p. 164). Not in some ways unlike a language genre, this FLC is set in a certain context, is social, and is a constructed activity in which peers can engage.

As for reflective practice, numerous definitions abound. Bailey, Curtis and Nunan (2004), cite several, from isolatory practice (Cruickshank \& Applegate; Richards \& Lockhart, 1994, p. 1), and in broader community contexts (Zeichner \& Liston, 1996, 1; Bartlett, 1990, p. 204). Farrel (2016, p. 98) asks how can novice teachers be better prepared, and argues for an in-depth development of reflective practice that would allow pre-service teachers to better manage their future multi-faceted teaching contexts. By extension the question could be raised to that of how best to prepare even experienced teachers when it comes to professional development, as the axiom "publish or perish" persists. An additional challenge noted by Rajagopalan (2014) is that of publishing in English, who states that "..it has become essential for ESL authors to prepare and publish their manuscripts in English, to succeed in the severely competitive world of academia" (paragraph 1). Braine (2003) offers two helpful observations for aspiring publishers: 1) an overview of the complete writing process (from conception to publication) as an individual author, and 2) the highlighting of the proliferation of academic journals having arisen in response to collegiate publishing demands to meet faculty publishing needs.

\section{Changing Contexts}

The progression from private school teaching to an 'apprenticeship of observation' in a university setting in early 2003 during my graduate school internship at PE Technikon (PET, now Nelson Mandela University) had been encouraging to me as I identified myself as being in an 'unknown validation' stage of teacher-learning. An obvious challenge for me at this time was being able to apply this new knowledge dependent on the future teaching context.

Undergoing experiential learning from SIT helped me quantify my skills and experiences as a learner and teacher, motivating me toward the PET environment. My internship at PET was a first chance to compare pedagogical differences between PET, SIT, and past academy teaching. This was a good initiation into how personal, social, and 
political events of communities and educational institutions can shape professional lives. Everything was different: the teaching content and assessment could be taught and tested as I desired, and there was additional time to experiment with new teaching techniques and materials.

At PET, I had been expectant, yet was still unprepared for the sense of community and professional sharing that existed. I finally felt like a member of a real community of teachers who were just as interested in my experiences and techniques as I was in theirs. Reflective practices heightened my self-development; community approaches broadened this, too. Through this internship, I was able to compare much of the why about how I had taught in Korea. I also began to recognize my evolving teacher identity, plus how and what methodologies to use in the classroom as I meshed 'learner' with 'teacher.' This curriculum finally demonstrated, to me, an internal shift from being just 'an English teacher' toward being an 'educator.'

At that time, I noted that being successful was going to be a balancing of teacher and student needs which would take time and practice, most likely through a process of continual renewal. Although I had taught for several years, I really only felt at the completion of this internship that I could call myself a true teacher. Joining and working with professional organizations, like TESOL (Teaching English to Speaker of Other Languages) had proven helpful to my personal and professional attitudes and career growth. Increased awareness of education management styles, educational institutions, communities and professional life made me more excited about figuring out how to better equip myself with the skills needed to keep apace of learning methodologies, approaches and student needs.

These past experiences at PET and SIT contributed to a strong sense of personal growth through varied sharing and learning processes. As a result, due to classroom observations and activities with others, I have questioned and challenged my 'known abilities' in the classroom. Understanding how significant my teacher-learner processes were in Korea, and how the differences between academies and the university environment have affected my motivation was a revelation to me. Reflecting on internship processes via journaling made me realize how influential my self-perception had been upon both of these teacher-learning environments. Recognizing the motivational variables that I can control as a teacher showed me that attaining success at different institutions and with different teaching communities is possible.

As mentioned, I became more aware of my values as an educator because my development as a teacher overseas was shaped significantly by my personal values. These values contributed to my workplace attitude due to the conflicting interplay between the personal and professional realms in my past and present teaching. Contrasting experiences between academy and internship teaching bolstered my awareness of workplace policies and procedures. Additionally, I came to fully realize the benefit of other perspectives through the peer evaluation at SIT.

\section{Awareness of my values as an educator}

My personal values play significantly into those that I hold as an educator. Learning about values and mores via familial and societal traditions seem always related to how we treat others and want to be treated, and this holds true for me as an educator. Being direct about my abilities and showing respectful openness to students is important; I still feel this way after nearly twenty years of teaching. I try to practice this with students and expect the same in return. Ironically, prior to attending SIT, I had never expressed my core values about my philosophy of teaching out loud to my students. I would say that I asserted my values into teaching, thinking they would be somehow absorbed by my students, but this was implicit wishing. While my values were definitely present during my teaching in Korea, I was able to be more expressive about those values through the MAT program at SIT.

Of importance to me in the classroom is honestly representing my teaching abilities and 'being myself.' I realized this perspective while journaling when I said:

It is therefore of great import that I not only be myself at that moment, but that I maintain an honest representation of my strengths and weaknesses in the classroom. To do this I feel that I have to have an awareness of who I am inside.

Incorporating more "personality" into my teaching had become an improving area of growth. I successfully experimented with this during the internship, and have continued to balance it against student expectations. 
Showing fairness while teaching means not always overwhelming the student with material. I like to give work representative to the task, plus at times give a little push to students. This promotes my belief that goals are to be 'achieved beyond', and not just 'achieved to.'

I demonstrated my valuing of this approach in an early memo, when I stated:

I want my students to understand the tasks I assign them in a way that makes sense to them. Providing the right kind of encouragement and/or insight to them in a challenging yet non-threatening way is of equal importance to me as a teacher, and is an area that I am diligently pursuing in my learning and teaching too.

Learning should be as fun as possible, but that does not mean that uneasy learning should be avoided. Consideration of my own past learning experiences that were challenging allowed me to show compassion for those who are must put forth more effort in their learning. Part of my responsibility as an educator is to make learning processes recognizable and valuable to students, and I can do this by remaining cognizant that every lesson has a performance goal.

\section{Attitudes of professionalism in my work}

Teaching in South Africa was a wonderful opportunity for me to challenge and refine perceptions about myself and my teaching. I enjoyed both the teaching and cultural exchanges there: meeting new coworkers; making new friends; and attending World Cup cricket matches. Early on in my journaling I reflected on how these experiences, including a work-free winter break, helped shape my attitudes about the internship:

It's good, feels good to be sharing my knowledge, but what feels even better is the sense of growth of my professional self in this career of teaching. This internship was a good choice for my psyche as well as for my future goals; I am glad that I came here.

What an understatement! This internship had proved to be one of the most significantly professional and personal events in my developing career to date. I felt quite validated in sharing my ideas on teaching, student learning, and culture with the PET staff, even as an intern.

Validation was not always easy for me in Korea, however. Having others evaluate my teaching was a worrisome event. Most new ${ }^{1}$ teachers had to orient by observing 'experienced' staff, and although I always did my best, I was still developing confidence in my abilities. This made me a little sensitive to how others might perceive my teaching style. Comments were appreciated, but disparagingly vague remarks like "good job" or "everything was fine" were just as ambiguous as the links I was trying to make between my own teaching gaps and students" learning.

It was for these reasons that I was looking forward to a second set of eyes in my internship teaching. Having others view my work creates a chance for me to improve upon it, and while I have been gaining more awareness of my strengths and how to improve past attempts through the fall term, I felt that this second perspective would be crucial to how I viewed my dilemma between balancing the realms of personality and professionalism in the classroom. My supervisor at PET was an excellent observer, and her comments in a final evaluation were personally vindicating:

Todd has an unflustered and professional in his approach to teaching. He was open to feedback and contributed positively and with insight into explanations for student behavior and for what happened in the classes. He got on well with both his colleagues and the students, demonstrating at all times an agreeable demeanor.

This kind of input was vital to my developing teacher skills, making me feel more aware of how these classroom skills reflected my own values and impacted upon student learning.

\section{Knowledge of policies, procedures, and practices of schools and educational institutions and how these impact} on my teaching

Having become more familiar school policies and procedures during my time at PET, allowed me to understand more easily how to deal with unforeseen complications. Shortly after beginning the internship, a contractual dispute between PET staff and management had delayed testing results, and subsequently, student placement in my classes. This latter delay led to improvised teaching schedules. I expressed my sentiments on the experience, and how this

\footnotetext{
${ }^{1} \mathrm{~A}$ "new" teacher was not necessarily inexperienced, but new to the school.
} 
delay in procedure could have had significant ramifications on both students and teachers in further journaling. Due to the delay, the teaching schedule had to be modified.

Observing and participating in this bureaucratic process gave me great insight on how procedural changes can be improvised. Proof of this was a series of firsts for me: teaching my largest classes ever (over 50 students), trying out CALL (Computer Assisted Language Learning) and basic computer teaching. Though at times the delays were frustrating, being flexible as well as open to new teaching formats allowed me to claim a successful internship experience. This was an experience I have often remembered, and has served me well in my present teaching: life happens, and students and teachers both have busy lives. Outside factors can influence all of this. It is in everyone's best interest to make things work for the benefit of the class and the program.

The differences between unexpected teaching delays, like at PET, versus institutionalized policies found in Korean private schools were quite large. Viewing these experiences within a framework of social, economic and political trends and events unique to each school helped me clarify my personal feelings about past and present procedures. It further allowed me to understand the unique context that each school type caters to, and what obstacles they have to overcome to claim success in their policies and student learning goals.

Teaching in Korean academies provided stability for my early teaching. The set curriculum allowed for supplementation as my teaching ability and confidence grew. Yet while I appreciated the opportunity to do this, knowing how to do was not always a smooth process. 'Difference' in educational contexts (Reynolds \& Trehan, 2003) can have its own rewards, however. Although the academy that I taught at was devoid of professional development opportunities, I was inspired by some truly wonderful coworkers. That experience, coupled with motivational variables in my classroom learning, was a determining factor in my motivation to seek, and continue to seek, professional development. We were able to discuss our teaching content at time, but for this to truly be more helpful, other conditions (Meyer, 2000) would need to be applied.

\section{Skills of inviting, understanding, and acting upon evaluations by colleagues and students}

Requested feedback sessions by an observing mentor in South Africa made me aware that my teaching style could use improvement. From this feedback, I learned how to better clarify my classroom practices as a teacher. My wanting to make sure that students were 'in the same place' versus what my observer expected, led specifically to a good discussion about my rationale for speaking slowly (in this case), and how to best improve upon other skills: pacing for different levels, gaining proficiency in expanding on the content related to context, and vocal tonality. This may be reflective of Woods' (1996, as cited in Bailey, Curtis \& Nunan, 2004)) idea of 'on-line decision making', where teachers are constantly engaged in micro-decisions as they teach (from Allwright \& Bailey, 1991, p. 25, as cited in Bailey, Curtis \& Nunan, 2004, p. 37). Nonetheless, I appreciated this feedback because scrutiny of this type made me work harder at associating the material in a way that students could understand better, and it forced me to justify my teaching rationale, which helped me understand it better, too.

Another area of growth at this time was that of materials development and evaluation. I had never had the time in my early teaching to make up many materials, only supplements like conversation handouts, quizzes and activity sheets. Taking a Curriculum Design and Four Skills (CDIA) courses filled in this gap of knowledge, though it was difficult. One example in a portfolio project that I did was applying a past Business English class to a curriculum format. I had never truly felt comfortable teaching this class in Korea, because I was conflicted about my teaching ability, plus I never knew how best to assess overall student learning, even though the four skills were incorporated into the book that I used. By re-developing a class that I had some familiarity with, I better understood how involved the overall process of course design can be, and how clear it must be from the teacher to the learners. The gains that I made via feedback given throughout this design process make me hopeful about designing future content and curricula.

My PE Technikon internship taught me more than just institutional policy and procedure. There was a newer class that exposed me to computer lesson planning. I was introduced to computer assisted language learning (CALL) due to schedule fluctuations. As a result, I volunteered to instruct PET students in PowerPoint and on-line reading tutorials in a computer learning laboratory. My excitement about this new medium was compounded by taking Educational Technology in a pre-internship course at SIT. 
This experience allowed for further growth. As a result of post-internship research on CALL, I presented a CALL workshop for a final graduation presentation, introducing basic history and online quiz-making applications to SIT peers and faculty. Having the attendees successfully make quizzes during the workshop was a very rewarding experience. The voluntary-feedback cards from my presentation solidified my feelings of proficiency in teaching basic CALL applications. Though I was not able to implement CALL in my later Korean contexts, I have used other online applications in recent years, like Edmodo and automated writing evaluation software for academic writing courses that I teach.

\section{Attitudes of valuing multilingualism and multiculturalism}

In my language and culture learning experiences I had come to appreciate the ability of how these two areas continually extended my learning boundaries. Learning Korean and Spanish were valuable experiences for me. The more that I learned about language, the more I felt that was gaining some insight into that culture, which in turn reinforced my attitude to keep learning. For example, learning Hangul helped me gain insight into Korean culture, and made me feel more involved in the culture, not just an observer of it. I relished my new insights and enjoyed learning more. As I began to study Spanish at SIT, I had again begun to feel a sense of understanding of culture through language, albeit in a different context.

Discussing language and cultural belief systems with others helped me appreciate linguistic and cultural diversity. My direct life experiences and involvement in past SIT workshops, like Diversity Training and 'Be A White Ally' helped me further understand and value the variety of languages and culture in many different contexts. Sometimes this learning was done by learning into my own discomfort about the use of language and its intention.

My exposure to multiple languages and cultures has impacted my outlook on life in the way the I communicate to others, what I want to show them about myself, and how I react to what they show me through their language and cultural belief systems. This is significant because actively participating in personal discussions can reveal how beliefs, attitudes and experiences play into personal growth. Moran (2001) says "Anyone immersed in the culture sees and hears the language all around. In this context, language and culture are clearly fused; one reflects the other" (p. 35). This is a thought reflective of my own personal experience. All of this serves to motivate me in life-long language and culture learning. This is no more evident than now being married to a Korean wife and having mixed (Korean-American) children.

The past multicultural and multilingual aspects of teaching in South Africa were impressive. Using English as a foundation for education and as a perceived model of economic prosperity made me consider the interplay of English with the students' L1 and L2 in the classroom. When I taught, I noticed that when doing group activities, students would primarily speak in a language other than English. My classes were composed of Xhosa, Afrikaans, White, Indian and Colored students. At the time, I reflected that:

It is good to see students expressing themselves with their native language. I think that as long as they are discussing about the class content, then using a language that my bolster that understanding is very useful. Many students speak at least three languages here; it is just a part of growing up in South Africa. What excellent diversity and understanding they must have or need to live their lives.

This example of my reasoning behind allowing language other than English and sporadic occasional code-switching during regular class time is still an approach that I use in present teaching, specifically in regard to peer feedback in academic writing classes. I feel that if the language being used is purposeful in moving the students toward the lesson objective, then it is an acceptable use in the class.

\section{Conclusion:-}

Finding one's voice in professional teaching is a truly wonderful process, but it does take time and commitment to understanding how one thinks about their profession, their approach to student learning and also teaching learning. It is a process that can be bridged by having a helpful group of managers and coworkers who discuss, share and challenge each other as they continue to progress and grow as professional teachers.

\section{Goals for Future Learning}

1. Continue to reflect/journal more on classroom teaching processes.

2. Attain student feedback on classroom techniques, processes, learning objectives, etc. 
3. Work on understanding the relationship of how policies and procedures of institutions can affect teacher development in EFL settings, for better and worse, both personally and professionally.

4. Plan and participate in formal and informal feedback sessions with peers and students, using a variety of methods (anonymous, group, individual, etc.).

5. Direct attention at how more global, 'non-place based' communities, like online communities of learning, can be created and maintained in my future teaching contexts.

6. Maintain active membership and engagement in professional organizations: AsiaTEFL, TESOL, Academia.com, etc.

7. Continue to research areas of interest and publish scholarly research journals.

\section{References:-}

1. Bailey, K. M., Curtis, A., Nunan, D. (2001). Pursuing Professional Development: The Self as Source. Heinle \& Heinle.

2. Braine, G. (2003). Negotiating the gatekeepers: The journey of an academic article. In Writing for scholarly publication (pp. 105-126). Routledge.

3. Hargreaves, A., \& Lo, L. N. (2000). The paradoxical profession: Teaching at the turn of the century. Prospects, 30(2), 167-180.

4. Engin, M. \& Atkinson, F. (2015). Faculty Learning Communities: A model for supporting curriculum changes in higher education. International Journal of Teaching and Learning in Higher Education. 27(2), 164-174.

5. Farrel, T. S. C., (2016). TESOL, a profession that eats its young! The importance of reflective practice in language teacher education. Iranian Journal of Language Teaching Research, 4(3), 97-107.

6. Meyer, T. (2000). Finding a Voice and Place in a Normative Profession.

7. Moran, P. (2001). Teaching Culture: Perspectives in Practice. Heinle \& Heinle: Singapore

8. Rajagopalan, J. (2014). Publish-In English-Or Perish? How ESL authors can overcome the language barrier. Editage Insights (11-07-2014).

9. Reynolds, M., \& Trehan, K. (2003). Learning from difference?. Management Learning, 34(2), 163-180. (abstract only)

10. Welton, M. (Ed.). (1995). In Defense of the Lifeworld. Suny, NY: State University of New York Press. In Reynolds, M. \& Trehan, Kiran (2003) 'Learning from Difference' Management Learning (journal) Vol. 34, No. 2, June

11. Woods, Peter (1994) The Conditions for Teacher Development. In Grimmett, Peter P. and Neufeld,Jonathan (Eds.) (1994) Teacher Development and the Struggle for Authenticity. Teachers College Press, Columbia University. p94-95. 